\title{
TIME-VARYING MACROECONOMIC IMPACTS OF GLOBAL ECONOMIC POLICY UNCERTAINTY TO A SMALL OPEN ECONOMY: EVIDENCE FROM INDONESIA
}

\author{
Sekar Utami Setiastuti ${ }^{12}$
}

\begin{abstract}
This paper studies macroeconomic impacts of global economic policy uncertainty shocks to a small open economy. To that end, I use monthly Indonesian data along with a measure of global economic policy uncertainty developed by Baker et al. (2016) and Davis (2016) and estimate a time-varying parameter Bayesian structural VAR with non-recursive identification using framework proposed by Canova and Pérez Forero (2015). I find that global economic policy uncertainty shocks lead to a reduction in prices, interest rate, and trade balance in all global events included in the estimation. The impact on output, however, largely varies across events. A surprise movement of global economic policy uncertainty triggers a contraction in output around the 2008 global financial crisis but, following the 2016 US presidential election, output reacts positively to the shock. Despite these notable variations in the responses of output, the proportion of the forecast error variance of output due to the shock is very small and decreases rapidly over time - which indicates that the shock presents an inconsequential effect to output. Nonetheless, the proportion of the forecast error variance of trade balance due to the shock is considerably higher than the forecast error variance of output and inflation. This further suggests that, via international trade, a global economic policy uncertainty shock could still pose harm for Indonesia.
\end{abstract}

Keywords: Global economic policy uncertainty shocks, Monetary policy, Small open economy, Bayesian structural VAR, Time-varying coefficients.

JEL Classification: C32, E32, E52, F41, F42

1 PhD candidate. Department of Economics, North Carolina State University. Email: susetias@ncsu.edu.

2 Teaching staff and researcher. Department of Economics, Universitas Gadjah Mada. 


\section{INTRODUCTION}

Baker et al. (2016) found that policy uncertainty contributes a significant share of business cycle in the US and several other developed countries. As mentioned by Caggiano et al. (2017), the importance of their paper is twofold. First, it studies the policy uncertainty as an independent source of business cycle fluctuations. Second, it confirms the findings of numerous studies that policy uncertainty may very well be the main driver of the fluctuations in the business cycle.

The bulk of the literature on economic policy uncertainty shocks, however, has mostly been carried out in a closed economy model framework. To a small open economy like Indonesia, this approach is not innocuous. Being open to the rest of the world, small open economies are prone to global and advanced countries' (e.g., the US, the EU, and Japan) business cycle fluctuations. $^{3}$

Moving away from the closed economy framework, Caggiano et al. (2017) estimated a nonlinear VAR model to study the impact of US economic policy uncertainty shocks on the Canadian economy. They suggested that the shocks explain a sizeable impact on Canadian unemployment rate, inflation, net export, and bilateral exchange rate. Furthermore, this impact is asymmetric and tend to be larger in crisis periods.

Similar to Caggiano et al. (2017), I depart from the autarkic framework and investigate the impact of global economic policy uncertainty (GPU, hereafter) shocks to Indonesian economy by modeling the transmission mechanism in a small open economy framework. In this paper, I ask the following questions: how do GPU shocks affect Indonesian economy? Do these effects vary across dates? How important are these shocks to the business cycle fluctuations in the economy? Do the contributions of the GPU shocks to Indonesian aggregates evolve over time?

The main novelty of this paper is twofold. First, using Indonesian data, I show that the transmission of GPU shocks to a small-open economy is time-varying. Second, I estimate the importance of these shocks to output, inflation, and trade balance and show that it varies across time. From a policymaker's perspective, GPU provides additional challenges to the decisionmaking process and this paper offers a relevant information to understand how the policy uncertainty in a global context can be costly to a small open country like Indonesia.

In my model, GPU arising in the global economy is allowed to affect the dynamics of macroeconomic variables in the domestic economy, with possibility of having time-varying effects depending on the source of GPU. Unlike Caggiano et al. (2017) who utilized US policy uncertainty data measured by Baker et al. (2016), I employ Davis (2016) GPU data which enables me to examine a broader source of economic policy uncertainty. In particular, I evaluate the impacts of GPU shocks around several important global events: (1) the Lehman Brother's collapse

3 For evidences in many countries, see Österholm and Zettelmeyer (2008); Abrego and Österholm (2008); and Andrle et al. (2013); and Solmaz and Sanjani (2015). 
in September 2008, (2) the European debt crisis in July 2011, (3) the "Bernanke shock" in May 2013, and (4) the US presidential election in November 2016. ${ }^{45}$

To capture the potentially time-varying effects of the GPU shocks, I estimate a time-varying parameters Bayesian structural VAR model (TVP-BVAR, hereafter) using a framework proposed by Canova and Pérez Forero (2015). ${ }^{6}$ In the estimation, I include monthly data from January 2000 to February 2017 with the following variables: (1) GPU index developed by Davis (2016) _ building on Baker et al. (2016), and macroeconomic variables consist of (2) total production in manufacturing - as a proxy for output, (3) headline CPI, (4) ratio of exports to imports-as a measure of international trade activity, (5) 3-months interbank rates-as a monetary policy rate, and (6) real effective exchange rate.

Finally, to provide a structural interpretation to the VAR equations and the model innovations, I apply a non-recursive short-run identification method (see, among others, Bernanke (1986); Blanchard and Watson (1986); Sims (1986); and Kim and Roubini (2000)). The non-recursive identification does not allow output, prices, trade balance, and monetary policy rate to react contemporaneously to GPU shock as I expect there are no within-a-month effects from GPU to these variables (because data is monthly). This identification, however, makes little sense if data is quarterly.

In all previously mentioned global events, I find that inflation, trade balance, and interest rate fall following GPU shocks. However, the responses of output to GPU shocks are different in all events. During the 2008 global financial crisis and the 2011 European debt crisis, GPU shocks lead to contraction in output and this finding is parallel to what Caggiano et al. (2017) found in Canada. Nevertheless, despite the recent concern about the US economic policy uncertainty post-2016 US presidential election, output increases following a GPU shock. The increase in output seems very counterintuitive, but it is not uncommon. Figure 2 in Colombo's (2013) study shows that when the US policy uncertainty shock hits the EU area, output rises on impact and declines only after three months.

To investigate how important is GPU shock to Indonesian economy, I show the forecast error variance decomposition due to GPU shock for various dates included in the data. Despite the perceptible variations in the impulse responses, the size of the forecast error variance of output and inflation due to GPU shocks is persistently small and the contribution of GPU shock in explaining the short-run dynamics of output is declining very quickly over time-which

4 I include the European Union debt crisis because, as one big economy, it is the largest economy in the world in 2011-the report can be downloaded from: http://ec.europa.eu/eurostat/documents/2995521/5178214/2-30042014-DP-EN.PDF/041aba7f-436c4dfd-acf6-157fac8b3bd9. Also, according to Observatory of Economic Complexity, value of exports to Euro area in 2015 accounts for around 12 percent of total exports, which is roughly similar to the value of exports to the US, China, and Japan.

5 The "Bernanke shock" was named after Ben Bernanke-a former US Federal Reserve Chairman, after in May 2013, he signaled the possibility that the Fed would end quantitative easing in the US.

6 In their paper, Caggiano et al. (2017) employs Smooth-Transition VAR framework. This, however, requires a good transition indicator as it is they key for the empirical exercises. My approach does not require such indicator. 
suggests that the GPU shocks pose no serious threats to the economy. In early 2005, GPU shock explains around 0.5 percent of the variability of output, but toward the end of sample period, the contribution of GPU shock to the variablity of output falls to 0.1 percent. In addition, GPU shock explains around 3 to 4.5 percent of the variability of trade balance-while, for comparison, it explains only around 0.04 percent of the forecast error variance of inflation at all dates. This result demonstrates that, via international trade, an uncertainty about global economic policies provides negative effects to a small open economy like Indonesia. But these effects are, arguably, inconsiderable.

The rest of paper is organized as follows. Section 2 presents the literature review. Section 3 describe the methodology. Section 4 discusses the results. Section 5 concludes.

\section{LITERATURE REVIEW}

This paper is directly related to the role of global or external economic policy uncertainty and its spillover effects in open economy context. Gauvin et al. (2014) studied the spillovers of policy uncertainty from advanced economies to emerging markets and found that a higher policy uncertainty in the US substantially reduces capital flows into emerging markets. Furthermore, these spillovers were highly dependent on global and domestic economic conditions. After global financial crisis in 2008, these effects are mostly channeled through financial market uncertainty. In addition, after "Bernanke shock", Aswicahyono and Hill (2014) mentioned that a group of countries dubbed as the "Fragile Five" — which include Brazil, India, Indonesia, South Africa, and Turkey, faced a twin shocks of capital reversal and a declining term of trade. In Indonesia, the capital flight started after the shock brought the Indonesian Stock Exchange (IDX) index down and triggered an exchange rate depreciation.

Focusing on the US and Canada, Caggiano et al. (2017) examined whether the US economic policy uncertainty affects Canadian business cycle fluctuations. The two countries were being chosen because they are highly interconnected and that shocks (such as total factor productivity, monetary policy, and fiscal policy shocks) originating in the US were shown to contribute to a significant proportion of the economic volatility in Canada. In their paper, they found a strong evidence of US economic policy uncertainty spillovers to Canadian business cycle, mainly in crises periods. Moreover, net exports show a significant, albeit short-lived, fall when the US economic policy uncertainty increases. Thus, they posited that a shock in the US policy uncertainty drives policy uncertainty in Canada, which consequently hurts Canada's net exports to the US and thus, induces a temporary contraction on Canadian output. This is what they called "trade channel".

Using a two-country structural VAR model, Colombo (2013) scrutinized the economic policy spillovers from the US to Euro area economy. Imposing short-run restrictions to identify the US policy shocks and employing a measure of policy uncertainty developed by Baker et al., 
she concluded that one standard deviation of US policy uncertainty generates a substantial reduction in the industrial production and prices in the EU area. In addition, both variables react greater to the US policy uncertainty shocks than to the Euro are-specific policy uncertainty shock. Six month after impact, the Euro area policy uncertainty shock explains for 2 percent of the industrial production whereas the US policy uncertainty shock contributes 4 percent of the variation of the variable. Moreover, the US policy uncertainty shock induces stronger changes in the Euro area consumer prices and policy rate, six times larger than the Euro area policy shock itself.

Klößner and Sekkel (2014) found that, among six developed countries, economic policy uncertainty is interconnected, with the US being the major country influencing the uncertainty in other countries included in the paper. ${ }^{7}$ Moreover, policy uncertainty spillovers contribute around 25 percent of the policy uncertainty dynamics in the countries. Using monthly data for the G7 countries on the sample period ranging from March 1971 through September 2010, Benigno et al. (2012) showed that policy uncertainty in the US, measured by time-varying volatilities of the monetary-policy shock, inflation target shock, and total factor productivity shock, is important factor driving the dynamics of macroeconomic variables in the countries.

Handley (2014) demonstrated the impact of uncertainties surrounding trade policy on exporter countries. He suggested that trade policy uncertainty hinder exporters' entry into new markets and consequently, induces a low responsiveness to tariff reductions. In another paper, Handley and Limão (2015) examined the impact of trade policy uncertainty on firms' investment and entry into new markets and they found that firms' exposure to GPU increased with globalization. Furthermore, they implied that a reduction of trade policy uncertainty boosts growth in entry.

\section{METHODOLOGY}

\subsection{Estimation Technique}

Following Primiceri (2005) and Canova and Pérez Forero (2015), the model in this paper is a multivariate time series with time-varying coefficients and time-varying variance covariance matrix.

Let $y_{t}$ be an $M \times 1$ vector of endogenous variables, $C_{t}$ be an $M \times 1$ vector of deterministic variables, and $u_{t} \sim N\left(0, \Omega_{t}\right)$ be heteroscedastic unobservable shocks with $\Omega_{t}$ be a symmetric, positive definite, and full rank variance covariance matrix, the model can be written as

$$
y_{t}=B_{0, t} C_{t}+B_{1, t} y_{t-1}+\ldots+B_{p, t} y_{t-p}+u_{t} \text {, for } t=1, \ldots, T
$$


where $B_{i, t}, i=1, \ldots, p$ are $n \times n$ matrices of time-varying coefficients and $B_{0, t}$ is a matrix containing the coefficients on $C_{t}$. Let the structural shock be $\epsilon_{t} \sim N(0, I)$ and $u_{t}=A_{t}^{-1} \Sigma_{t} \epsilon_{t}$ where $A_{t} \equiv A\left(\alpha_{t}\right)$ is the matrix of contemporaneous coefficient, $\alpha_{t}$ is a vector of unrestricted parameters, and the matrix $\Sigma_{t}=\operatorname{diag}\left(\sigma_{m, t}\right)$ contains the standard deviations of $\epsilon_{t}$ in the main diagonal, the structural VAR can be written as

$$
y_{t}=B_{0, t} C_{t}+B_{1, t} y_{t-1}+\ldots+B_{p, t} y_{t-p}+A_{t}^{-1} \Sigma_{t} \epsilon_{t}
$$

Let $X_{t}^{\prime}=I \otimes\left[C_{t}^{\prime}, y_{t-1}^{\prime}, \ldots, y_{t-p}^{\prime}\right]$ and $B_{t}=\left[\operatorname{vec}\left(B_{0, t}\right)^{\prime}, \operatorname{vec}\left(B_{1, t}\right)^{\prime}, \ldots, \operatorname{vec}\left(B_{p, t}\right)^{\prime}\right]^{\prime}$, the above equation can be written as,

$$
y_{t}=X_{t}^{\prime} B_{t}+A_{t}^{-1} \Sigma_{t} \epsilon_{t}
$$

where $X_{t}^{\prime}$ and $B_{t}$ are $M \times K$ matrix and $K \times 1$ vector, $K=M \times M+p M^{2}$. The estimation strategy consists of modelling (3) by assuming that the dynamics of the time-varying parameters is

$$
\begin{aligned}
& \alpha_{t}=\alpha_{t-1}+u_{t}, \\
& B_{t}=B_{t-1}+v_{t}, \\
& \log \sigma_{m, t}=\log \sigma_{m, t-1}+\eta_{t} .
\end{aligned}
$$

Although, a random walk process hits any lower or upper bound with probability one, as mentioned by Primiceri (2005), if (4) - (6) are in place for a finite period, these assumptions are harmless.

Let $\eta_{t}=\left[\eta_{1, t}, \ldots, \eta_{M, t}\right]$ and let $Q, V, W$ be full rank matrices, set the variance covariance matrix,

$$
\mathcal{V}=\operatorname{Var}\left(\left[\begin{array}{c}
\epsilon_{t} \\
v_{t} \\
u_{t} \\
\eta_{t}
\end{array}\right]\right)=\left[\begin{array}{cccc}
I_{N} & 0 & 0 & 0 \\
0 & Q & 0 & 0 \\
0 & 0 & V & 0 \\
0 & 0 & 0 & W
\end{array}\right] .
$$

This setup describes the time variations in: (a) contemporaneous reaction coefficients in (4), (b) the lag structure in (5), (c) and the structural variances in (6).

Now consider a model obtained by estimating the reduced-form VAR in (1),

$$
A\left(\alpha_{t}\right)\left(y_{t}-X_{t}^{\prime} \widehat{B}_{t}\right) \equiv A\left(\alpha_{t}\right) \hat{y}_{t}=\Sigma_{t} \epsilon_{t}
$$

Letting $\operatorname{vec}\left(A\left(\alpha_{t}\right)\right)=S_{A} f_{t}+s_{A}, S_{A}$ and $s_{A}$ are matrices with $1 s$ and $0 s$ with dimensions of $M^{2} \times \operatorname{dim}\left(f\left(\alpha_{t}\right)\right)$ and $M^{2} \times 1$, equation (8) can be reparametrized as follows

$$
\left(\hat{y}_{t} \otimes I\right)\left(s_{A} f_{t}+s_{A}\right)=\Sigma_{t} \epsilon_{t}
$$


where the state space is composed of

$$
\begin{aligned}
& \tilde{y}_{t}=Z_{t} f_{t}+\Sigma_{t} \epsilon_{t}, \\
& f_{t}=f_{t-1}+\zeta_{t}
\end{aligned}
$$

and (6). Given $\left(\widehat{B^{T}}, \Sigma^{T}, \mathcal{V}\right)$, we should draw $f^{T} \equiv\left\{f_{t}\right\}_{t=1}^{T}$ from $p\left(f^{T} \mid \tilde{y}^{T}, \Sigma^{T}, \mathcal{V}, \widehat{B^{T}}\right)$. In Primiceri (2005), $f_{t}$ are partitioned into blocks, say $f_{t}=\left[f_{1 t}^{\prime}, \ldots, f_{M t}^{\prime}\right]^{\prime}$, which are associated with each equation. These blocks are assumed to be independent, or $\mathcal{V}=\operatorname{diag}\left(\mathcal{V}_{1}, \ldots, \mathcal{V}_{M}\right)$. Thus,

$$
p\left(f^{T} \mid \tilde{y}^{T}, \Sigma^{T}, \mathcal{V}, \widehat{B^{T}}\right)=\prod_{m=2}^{M} p\left(\left(f^{m}\right)^{T} \mid\left(f^{m-1}\right)^{T}, \tilde{y}^{T}, \Sigma^{T}, \mathcal{V}, \widehat{B^{T}}\right) \times p\left(\left(f^{1}\right)^{T} \mid \tilde{y}^{T}, \Sigma^{T}, \mathcal{V}, \widehat{B}^{T}\right) .
$$

Note that this setup enables an equation by equation estimation. Nevertheless, because each element of $\alpha_{t}$ in this model is assumed to have economic meanings, $V$ cannot be diagonal. Canova and Pérez Forero (2015) developed an algorithm to relax this assumption. They proposed an algorithm of which the vector $f_{t}$ is jointly drawn and $V$ is not block diagonal. By relaxing these assumptions, the model can handle recursive, as well as non-recursive and just-identified, as well as over-identified models in a unified framework. The general algorithm they proposed is the following:

1. Set initial values $\left(\left(B^{0}\right)^{T},\left(f^{0}\right)^{T},\left(s^{0}\right)^{T},\left(\Sigma^{0}\right)^{T}, \mathcal{V}^{0}\right)$.

2. For $i=1, \ldots, G, \operatorname{draw}\left(B^{i}\right)^{T}$ from

$$
p\left(\left(B^{i}\right)^{T} \mid \tilde{y}^{T},\left(f^{i-1}\right)^{T},\left(s^{i-1}\right)^{T},\left(\Sigma^{i-1}\right)^{T}, \nu^{i-1}\right) \cdot I_{B}\left(B_{i}^{T}\right),
$$

where the posteriors are truncated by $I_{B}\left(B_{i}^{T}\right)$ to make sure that the impulse responses are stationary. Then, $p(\cdot)$ is normal and is computed using Kalman filter recursions and a multimove Carter-Kohn (1994).

3. $\operatorname{Draw}\left(f^{i}\right)^{T}$ from

$$
p\left(\left(f^{i}\right)^{T} \mid \tilde{y}^{T},\left(s^{i-1}\right)^{T},\left(\Sigma^{i-1}\right)^{T}, \nu^{i-1},\left(B^{i}\right)^{T}\right)
$$

using the following algorithm. First, set $f_{0 \mid 0}$ and $P_{0 \mid 0}$. Then, for $i=1, \ldots, G$, do these steps.

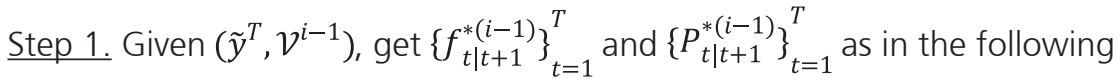

$$
\begin{aligned}
& f_{t \mid t+1}^{*}=f_{t \mid t}+P_{t \mid t} Z_{t}^{\prime} P_{t+1 \mid t}^{-1}\left(f_{t+1 \mid t+2}^{*}-Z_{t}^{\prime} f_{t \mid t}\right), \\
& P_{t \mid t+1}^{*}=P_{t \mid t}+P_{t \mid t} Z_{t}^{\prime} P_{t+1 \mid t}^{-1} Z_{t}^{\prime} P_{t \mid t-1}^{-1}, t=T-1, \ldots 1 .
\end{aligned}
$$

1. For $t=1 \ldots, T$, draw $f_{t}^{\Delta} \sim p_{*}\left(f_{t}^{i} \mid f_{t}^{i-1}\right)=t\left(f_{t \mid t+1}^{*(i-1)}, r P_{t \mid t+1}^{*(i-1)}, v\right), \gg 0$, and $v \geq 4$.

2. Set $\left(f^{\Delta}\right)^{T} \equiv\left\{f_{t}^{\Delta}\right\}_{t=1}^{T}$ and $p_{*}\left(\left(f^{i}\right)^{T} \mid\left(f^{i-1}\right)^{T}\right)=\prod_{t=1}^{T} p_{*}\left(f_{t}^{i} \mid f_{t}^{i-1}\right)$, then compute 


$$
\theta=\frac{p_{*}\left(\left(f^{\Delta}\right)^{T} \mid \tilde{y}^{T}\right) \cdot p_{*}\left(\left(f^{i-1}\right)^{T} \mid\left(f^{i}\right)^{T}\right)}{p_{*}\left(\left(f^{i}\right)^{T} \mid \tilde{y}^{T}\right) \cdot p_{*}\left(\left(f^{i}\right)^{T} \mid\left(f^{i-1}\right)^{T}\right)}
$$

where the posterior kernel of $\left(f^{\Delta}\right)^{T}$ and $\left(f^{i-1}\right)^{T}$ is

$$
p\left(\cdot \mid \tilde{y}^{T}\right)=L\left(\tilde{y}^{T} \mid\left(\cdot \mid \mathcal{V}^{i-1}\right) \cdot\left[p(\cdot)^{T} \mathcal{J}(f)\right]\right)
$$

and $\mathcal{J}(f)$ is an indicator which restricts the prior distribution.

1. Draw $v \sim U(0,1)$. Set $\left(f^{i}\right)^{T}=\left(f^{\Delta}\right)^{T}$ if $v<\theta$ and $\left(f^{i}\right)^{T}=\left(f^{i-1}\right)^{T}$ otherwise.

Step 2. Given $\left(\tilde{y}^{T},\left(f^{i}\right)^{T}\right)$, draw

$$
\left(V^{i}\right)^{-1} \sim p\left(\left(V^{i}\right)^{-1} \mid\left(f^{i}\right)^{T}, \tilde{y}^{T}\right)=W\left(\bar{v}_{V}, \bar{V}^{-1}\right)
$$

where the prior parameters are

$$
\begin{aligned}
& \bar{v}_{V}=T+\underline{v}_{V^{\prime}} \\
& \bar{V}^{-1}=\left[\underline{V}+\sum_{t=1}^{T}\left(f_{t}^{i}-f_{t-1}^{i}\right)\left(f_{t}^{i}-f_{t-1}^{i}\right)^{\prime}\right]^{-1} .
\end{aligned}
$$

4. Given $\left(\hat{y}^{T},\left(B^{i}\right)^{T},\left(f^{i}\right)^{T}\right)$, the model is linear and can be written as

$$
\widehat{A}\left(\alpha_{t}\right) \hat{y}_{t} \equiv y_{t}^{* *}=\Sigma_{t} \epsilon_{t}
$$

and (6), where $\operatorname{vec}\left(\widehat{A}\left(\alpha_{t}\right)\right)$ is the matrix of contemporaneous coefficients evaluated at the current draw $\left(f^{i}\right)^{T}$. Note that $\epsilon_{m, t}$ is Gaussian, thus $\log \epsilon_{m, t}^{2}$ in

$$
y_{m, t}^{*}=\log \left[\left(y_{m, t}^{* *}\right)^{2}+\bar{c}\right] \approx 2 \log \left(\sigma_{m, t}\right)+\log \epsilon_{m, t}^{2}
$$

is $\log \left(\chi^{2}\right)$ distributed and can be approximated using a mixture of normal distributions.

5. Given $\left(\left(y^{* *}\right)^{T},\left(B^{i}\right)^{T},\left(f^{i}\right)^{T},\left(\Sigma^{i-1}\right)^{T}\right)$, draw $\left(s^{i}\right)^{T}$ and get

$$
P\left(s_{m, t}=j \mid y_{m, t}^{* *} \log \left(\sigma_{m, t}\right)\right) \propto q_{j} \times \phi\left(\frac{y_{m, t}^{* *}-2 \log \left(\sigma_{m, t}\right)-\eta_{j}+1.2704}{\gamma_{j}}\right)
$$

where $j=1, \ldots, J, q_{-} j$ is a set of weights, and $\gamma_{j}$ and $\eta_{j}$ are the standard deviation and mean of the $j$ th mixture, respectively. Then, draw $u \sim U(0,1)$ and set $s_{m, t}=j$ if $P\left(s_{m, t} \leq j-1 \mid y_{m, t}^{* *}, \log \left(\sigma_{m, t}\right)\right)<u \leq P\left(s_{m, t} \leq j \mid y_{m, t}^{* *} \log \left(\sigma_{m, t}\right)\right)$.

6. Given $\left(\tilde{y}^{T},\left(B^{i}\right)^{T},\left(f^{i}\right)^{T},\left(s^{i}\right)^{T}\right)$, Kalman smoother recursions is used to draw $\left\{\Sigma_{t}\right\}_{t=1}^{T}$ from (1), (3)-(7) and $s^{\wedge} \mathrm{T}$ is obtained from step 5. To make sure that structural variances are independent, sample each $\sigma_{m, t}$ assuming diagonal $W$.

7. Lastly, draw $\mathcal{V}^{i}$ from $p\left(\mathcal{V}^{i} \mid \tilde{y}^{T},\left(f^{i}\right)^{T},\left(s^{i}\right)^{T},\left(\Sigma^{i}\right)^{T},\left(B^{i}\right)^{T}\right)$. When sampling $\mathcal{V}^{i}$, it is assumed that each block is independent inverted Wishart distribution. Then, use $\left(f^{i}\right)^{T},\left(s^{i}\right)^{T},\left(\Sigma^{i}\right)^{T},\left(B^{i}\right)^{T}$, and $\mathcal{V}^{i}$ as initial values and repeat the sampling. 


\subsection{Empirical Model}

I apply the TVP-BVAR estimation method proposed by Canova and Pérez Forero (2015) to estimate the macroeconomic impact of GPU shocks to the Indonesian economy. The variables included in the model are monthly data of (1) global economic policy index (GPU), (2) total production in manufacturing (IP) as a measure of output, (3) headline $\mathrm{CPI}(\mathrm{P}),(4)$ ratio of exports to imports $(\mathrm{XM})$ as a measure of trade balance, (5) 3-months interbank rate $(\mathrm{R})$ as the monetary policy rate, and (6) real effective exchange rate (X). The GPU index was constructed by Davis (2016), building on Baker et al. (2016). This index is a GDP-weighted average of economic policy uncertainty index for 16 countries — which account for two-thirds of world's GDP_and the economic policy uncertainty index for each country describes the relative frequency of its newspaper articles which contain the terms relevant to the economy, uncertainty, and policyrelated issues.

The sample runs from January 2000 to February 2017 and the data was collected from Federal Reserve Bank of St. Louis economic database, except for the GPU index. ${ }^{8}$ All variables in the model are standardized (i.e., $\left(y_{t}-E\left(y_{t}\right)\right) / \operatorname{std}\left(y_{t}\right)$ and are expressed in year-to-year rate changes (i.e., $y_{t}=\log \left(y_{t}\right)-\log \left(y_{t-12}\right)$, except for the monetary policy rate. Figure 1 shows the transformed data used in the estimation.

Then, to give economic meaning to the structural parameters, I identify the model using exclusion restrictions as follows:

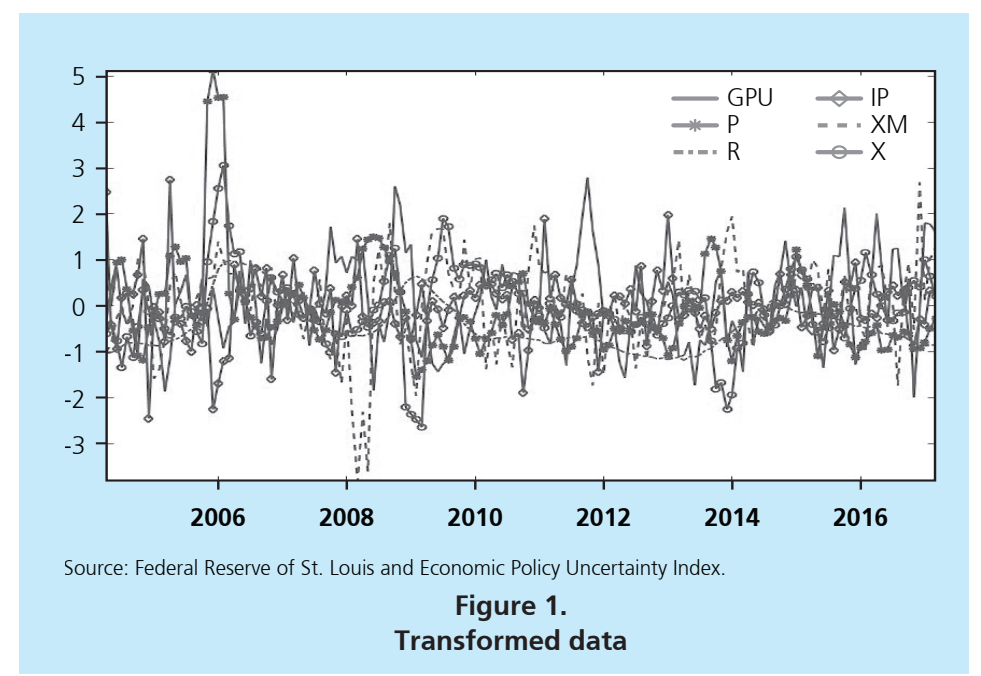


1. Real effective exchange rate (REER) reacts contemporaneously to all structural shocks. This identification is consistent with previous open economy VAR studies, such as Kim and Roubini (2000) and Voss and Willard (2009). As a forward-looking asset price and an arbitrage equation that characterize financial market equilibrium, all variables are assumed to contemporaneously affect exchange rate.

2. The monetary policy rate is used as instrument to target inflation and output, thus reacts contemporaneously to changes in both variables.

3. Ratio of exports to imports reacts contemporaneously to structural shocks of output and REER.

4. Headline CPI reacts contemporaneously only to output. Following Bernanke and Blinder (1982), inflation is assumed to react to all other variables only with delay.

5. Production in manufacturing, as a proxy of output, do not react to all structural shocks contemporaneously.

6. The GPU index also reacts to all structural shocks only with a delay.

Let $\epsilon_{t}=\left[\epsilon_{t}^{\mathrm{GPU}}, \epsilon_{t}^{\mathrm{IP}}, \epsilon_{t}^{\mathrm{CPI}}, \epsilon_{t}^{\mathrm{XM}}, \epsilon_{t}^{\mathrm{R}}, \epsilon_{t}^{\mathrm{X}}\right]$ be the vector of structural shocks. Given the identification, the structural model can be written as

$$
\underbrace{\left[\begin{array}{cccccc}
1 & 0 & 0 & 0 & 0 & 0 \\
0 & 1 & 0 & 0 & 0 & 0 \\
0 & \alpha_{2, t} & 1 & 0 & 0 & 0 \\
0 & \alpha_{3, t} & 0 & 1 & 0 & \alpha_{10, t} \\
0 & \alpha_{4, t} & \alpha_{6, t} & 0 & 1 & 0 \\
\alpha_{1, t} & \alpha_{5, t} & \alpha_{7, t} & \alpha_{8, t} & \alpha_{9, t} & 1
\end{array}\right]}_{A\left(\alpha_{t}\right)} \times\left[\begin{array}{c}
\mathrm{GPU}_{t} \\
\mathrm{IP}_{t} \\
\mathrm{CPI}_{t} \\
\mathrm{XM}_{t} \\
\mathrm{R}_{t} \\
\mathrm{X}_{t}
\end{array}\right]=A_{t}^{+}(L)\left[\begin{array}{c}
\mathrm{GPU}_{t-1} \\
\mathrm{IP}_{t-1} \\
\mathrm{CPI}_{t-1} \\
\mathrm{XM}_{t-1} \\
\mathrm{R}_{t-1} \\
\mathrm{X}_{t-1}
\end{array}\right]+\Sigma_{t}\left[\begin{array}{c}
\epsilon_{t}^{\mathrm{GPU}} \\
\epsilon_{t}^{\mathrm{IP}} \\
\epsilon_{t}^{\mathrm{CPI}} \\
\epsilon_{t}^{\mathrm{XM}} \\
\epsilon_{t}^{\mathrm{R}} \\
\epsilon_{t}^{\mathrm{X}}
\end{array}\right]
$$

where $A_{t}^{+}(L)$ is a function of $B_{t}$ and $A\left(\alpha_{t}\right)$ and $\Sigma_{t}$, the matrix of standard deviations of the structural shocks is given by

$$
\Sigma_{t}=\left[\begin{array}{cccccc}
\sigma_{t}^{\mathrm{GPU}} & 0 & 0 & 0 & 0 & 0 \\
0 & \sigma_{t}^{\mathrm{IP}} & 0 & 0 & 0 & 0 \\
0 & 0 & \sigma_{t}^{\mathrm{CPI}} & 0 & 0 & 0 \\
0 & 0 & 0 & \sigma_{t}^{\mathrm{XM}} & 0 & 0 \\
0 & 0 & 0 & 0 & \sigma_{t}^{\mathrm{R}} & 0 \\
0 & 0 & 0 & 0 & 0 & \sigma_{t}^{\mathrm{X}}
\end{array}\right]
$$

The structural model (23) is non-recursive and overidentified by five restrictions. Two lags are used in the estimation and the simulations are based on 150,000 draws, discarding the first 100,000 draws, and keeping 1 out of every 100 of the remaining for inference-or the thinning factor is 10 . The lag is optimally chosen by AIC. 
The priors are proper, conjugate, and are given by the following: $\alpha^{\text {prior }} \sim N(\overline{\boldsymbol{\alpha}}, \operatorname{diag}(\operatorname{abs}(\overline{\boldsymbol{\alpha}})))$, $B_{0}^{\text {prior }} \sim N(\overline{\mathbf{B}}, 4 \cdot \overline{\mathbf{V B}}), Q^{\text {prior }} \sim \operatorname{IW}\left(k_{Q}^{2} \cdot \overline{\mathbf{V B}},(1+K)\right), S^{\text {prior }} \sim \operatorname{IW}\left(k_{S}^{2} \cdot \operatorname{diag}(\operatorname{abs}(\overline{\boldsymbol{\alpha}})),(1+\operatorname{dim} \alpha)\right)$, $\log \left(\sigma_{0}\right)^{\text {prior }} \sim N\left(\overline{\boldsymbol{\sigma}}, 10 \cdot I_{M}\right)$, and $W_{i}^{\text {prior }} \sim \operatorname{IW}\left(k_{W}^{2}, 1+1\right)$, for $i=1, \ldots, M$. To fine tune the hyperparameters, I estimate a version of the model with constant coefficient using the first 36 observations as a training sample. In this estimation, $\overline{\boldsymbol{\alpha}}$ and $\overline{\boldsymbol{\sigma}}$ are estimated using maximum likelihood using 10 different starting points and $\overline{\mathbf{B}}$ and $\overline{\mathbf{V B}}$ are obtained using OLS. Following Canova and Pérez Forero (2015), I set $k_{Q}^{2}=0.5 \times 10^{-4}, k_{S}^{2}=1 \times 10^{-3}, k_{W}^{2}=1 \times 10^{-4}$, and $J=7$.

To draw $B^{T}$, I use Carter and Kohn's (1994) multi-move strategy where the components of $B^{T}$ are sampled jointly from normal distributions which moments are centered at Kalman smoother estimates. If stability condition fails, draws for $B_{t}$ are discarded and to eliminate outlier draws, I use the function $I(f)$ which is uniform over the interval $(-20,20)$. In my application, 97.33 percent of draws were inside the bounds and the acceptance rate for the Metropolis step sampling is 42.09 percent.

\section{RESULT AND ANALYSIS}

\subsection{Empirical Result}

In Figure 2, I report the highest 68 percent posterior tunnel for the variability of shocks of all variables. There are several interesting results emerge from this figure. First, the standard deviations of GPU shocks show a slight upward trend. Second, output is becoming more and more stable over time. Thus, despite the more volatile GPU, this may demonstrate that macroeconomic policy in the country has been successful in stabilizing output and has been better shielding the economy from external policy uncertainty shocks. Third, there are large spikes in the standard deviation of the headline CPI inflation in late 2005 and late 2014. These large upswings were mostly driven by Indonesian government's decision to reduce the amount of fuel subsidies for its citizens. Lastly, there are large fluctuations in the standard deviations of monetary policy shocks around the time when fuel subsidies were being reduced. This pattern is expected, given the identification restrictions. 

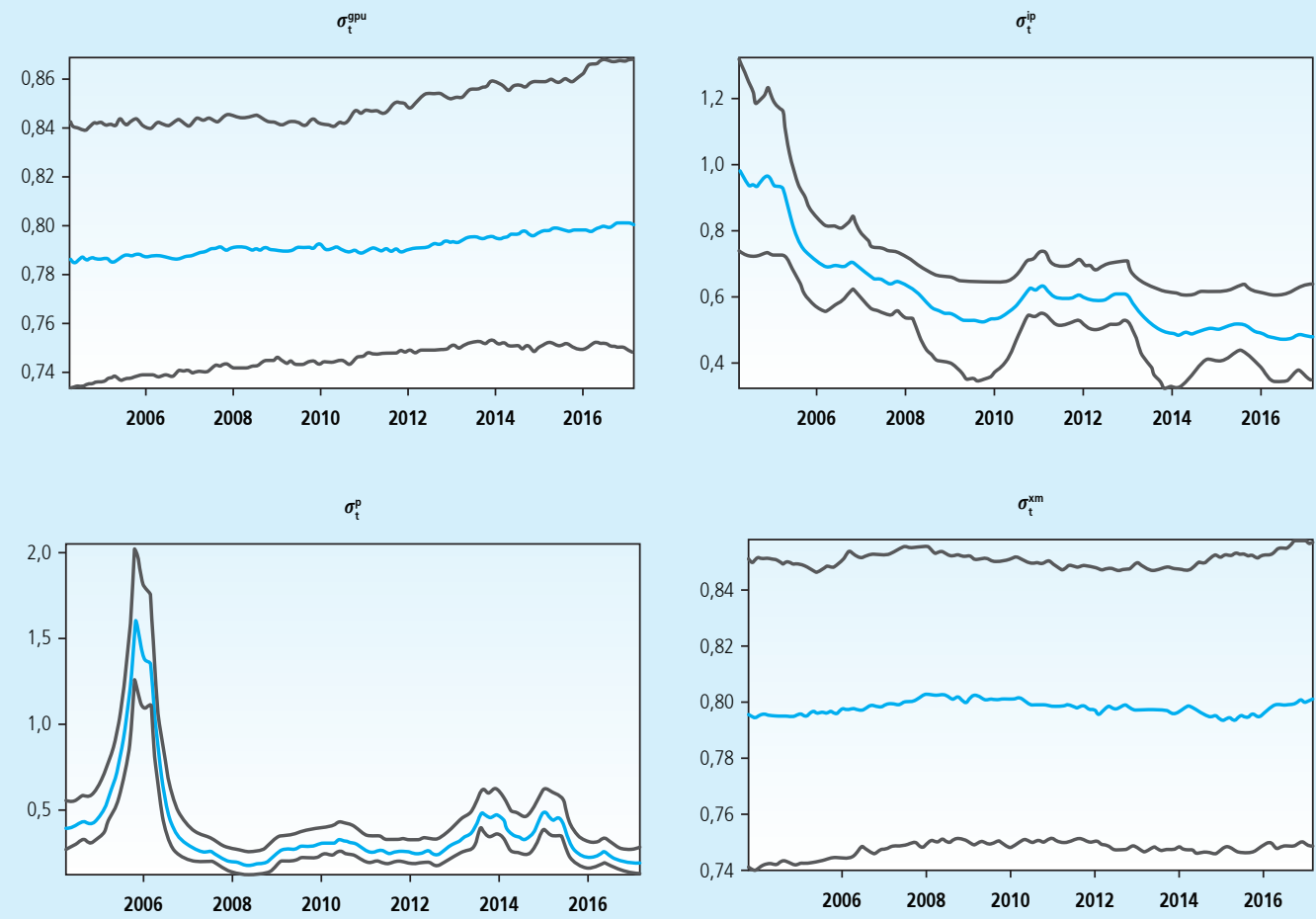

$\sigma_{\mathrm{t}}^{\mathrm{r}}$
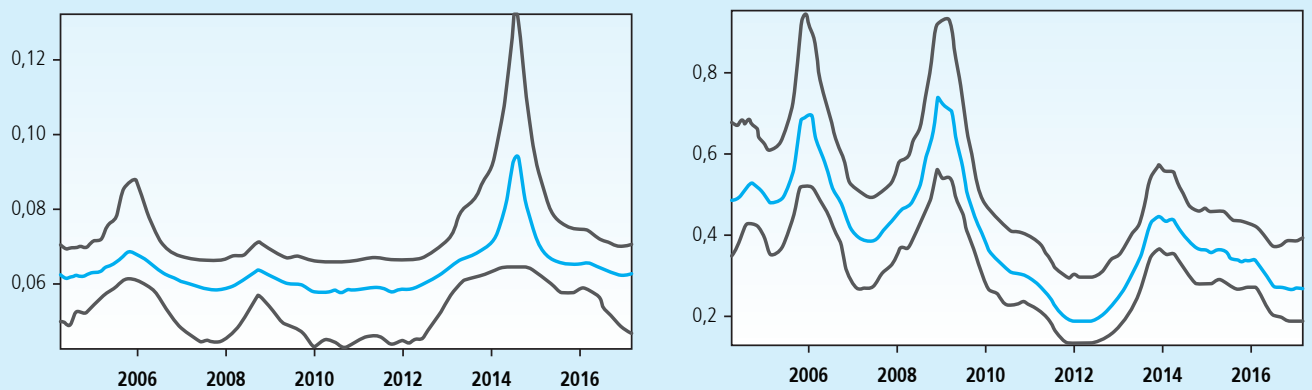

Figure 2.

Median and 68 percent posterior tunnels of volatility of all shocks: various dates.

Figure 3 shows the highest 68\% posterior tunnel for the contemporaneous structural coefficients $\alpha_{t}$. The policy parameters $\alpha_{4, t}$ and $\alpha_{6, t}$ which controls the reaction of nominal interest rates to output and inflation exhibit large time variations but there is no apparent trend (upward nor downward) in these variations. The sign and magnitude of these parameters exhibit large time variations which are a posteriori significant. Also, note that the magnitude of $\alpha_{6, t}$ is larger than $\alpha_{4, t}$ throughout the sample period suggesting that the central bank is responding to inflation greater than to output. 

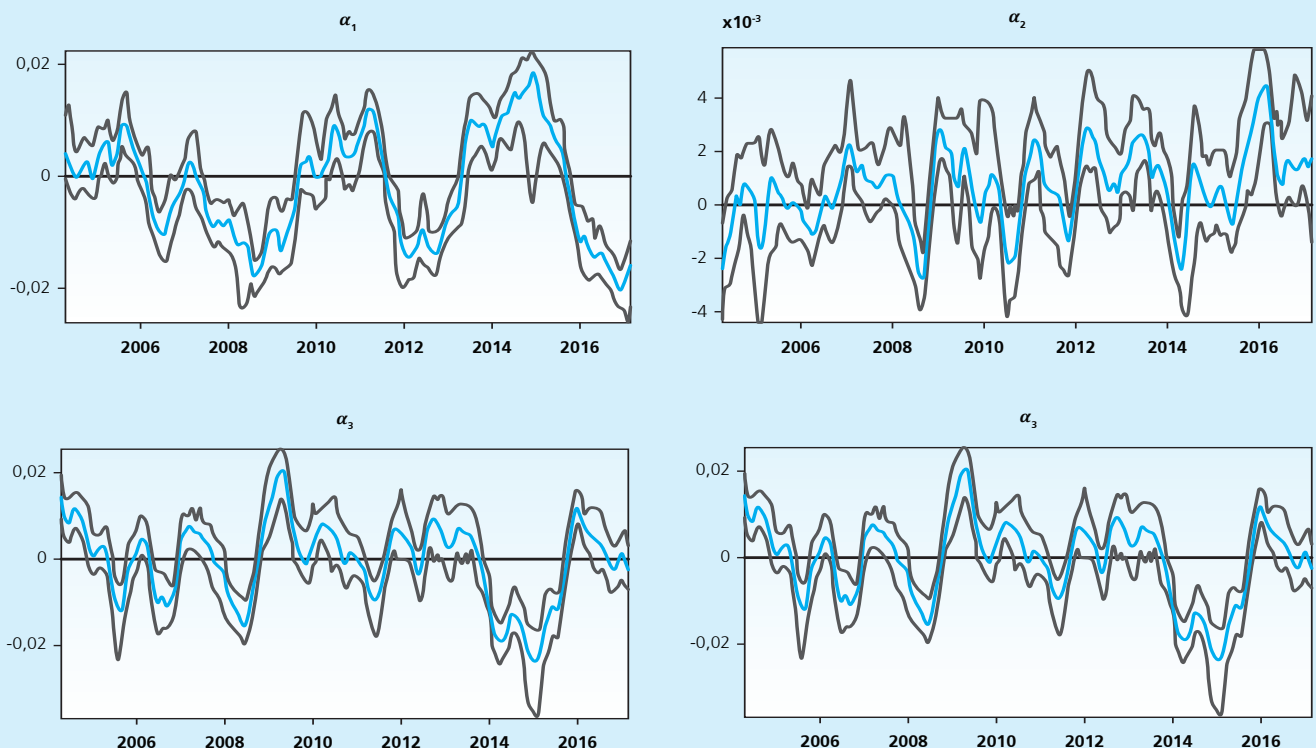

$\alpha_{5}$
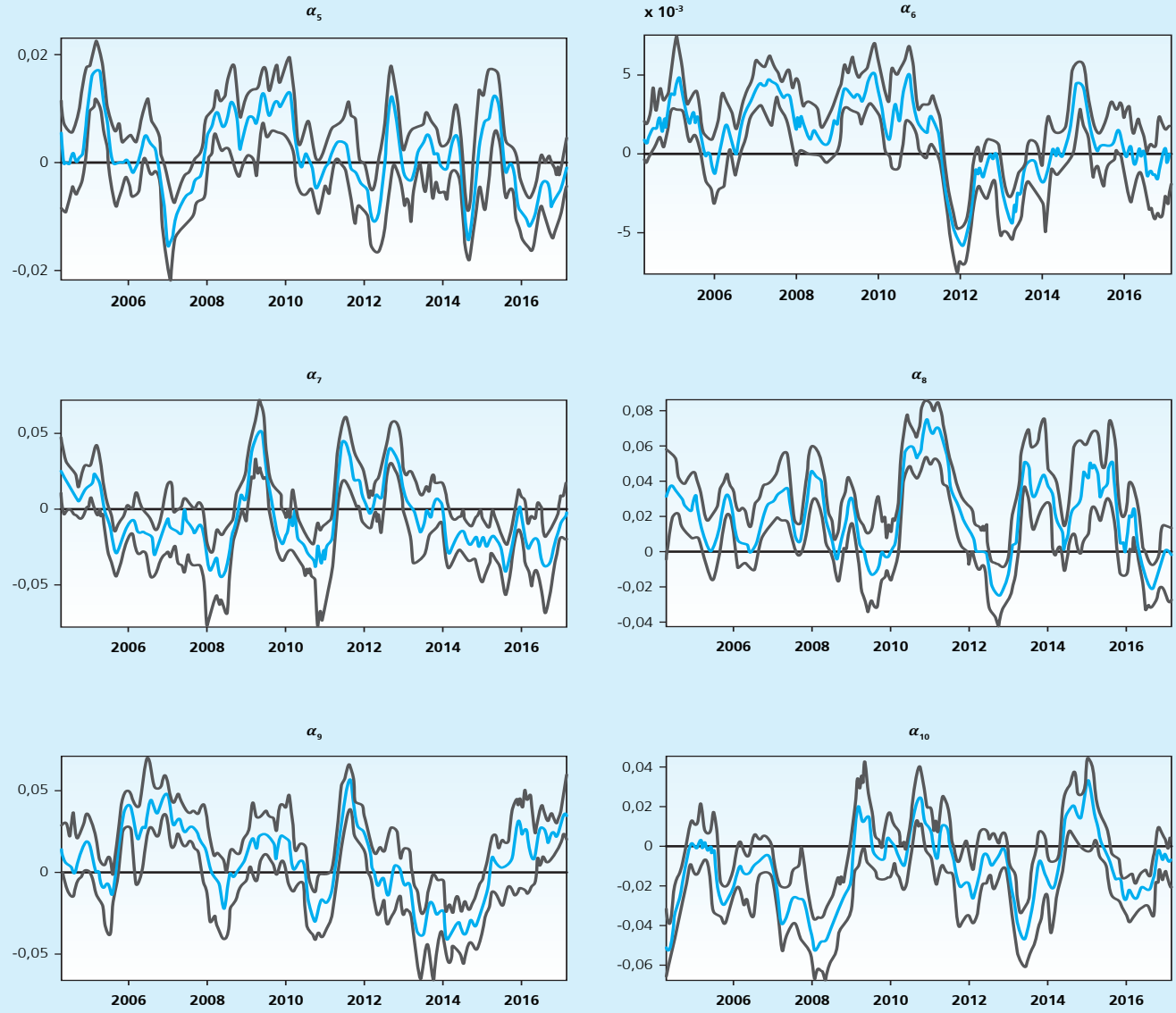

Figure 3. Estimates of $\alpha \_t$. 
Similarly, the contemporaneous effect of GPU to exchange rate $\alpha_{1, t}$ also displays considerable time variation and is unstable throughout the sample. However, note that after the "Bernanke shock", the sign is mostly positive but around the 2008 global financial crisis and the 2016 US presidential election, it is always negative. These changes in sign may mean two things. First it may demonstrate how different sources of GPU lead to distinctive impacts on the exchange rate. Second, it may indicate that GPU shocks are not the main driver of exchange rate determination in the economy.

Next, l evaluate how the time variations of the structural parameters affect the transmission of GPU shock. Following Canova and Pérez Forero (2015), I normalize the impulse responses to 1 at all t. Hence, time variations of the responses are caused by how the shocks are propagated, and not by the size of the shocks. In addition, the responses are computed as the difference between conditional projections, when the structural shock is set to 1 and when it is set to 0 . The results are the following.

First, the responses of output to GPU shocks are largely different in all global events included in this study. During the 2008 global financial crisis and the 2011 European debt crisis, GPU shocks lead to contraction in output. In these events, output falls immediately after the shock, but it quickly bounces back to its pre-shock level after 9 months. This finding is parallel to what Caggiano et al. (2017) found in Canada and as mentioned by Colombo (2013), a higher uncertainty surrounding economic policy forces firms and households to delay their investment and consumption decision-due to the option value of waiting and to a precautionary savingmotive. However, despite the recent concern about the US economic policy uncertainty around the 2016 US presidential election, output reacts positively to the shock and rapidly moves back to its pre-shock level after 9 months. The result sounds counterintuitive but it is not uncommon. Figure 2, in Colombo (2013), shows that when the US policy uncertainty shock hits the EU area, output increases on impact and only declines three months after the shock hits the economy.

Second, GPU shocks trigger reductions in prices and interest rate. Unlike output, the responses of these variables do not vary much across events. When output also falls, as mentioned by Colombo (2013), the deflationary behavior of prices is consistent with demanddriven price determination-the fall in aggregate demand drags the prices down. Note that, given that the central bank pursues inflation-targeting policy, the decrease in interest rate is predictable and the similarity between the responses of inflation across events suggests the ability of monetary policy to stabilize prices has not changed over time.

Third, following GPU shocks, trade balance falls significantly in all events. These responses mimic the responses found by Caggiano et al. (2017) for the case of Canada. GPU shocks immediately reduce global demand for Indonesian export products. Nevertheless, these contractions are short-lived. The responses rapidly rebound to their pre-shock level after 12 months. 

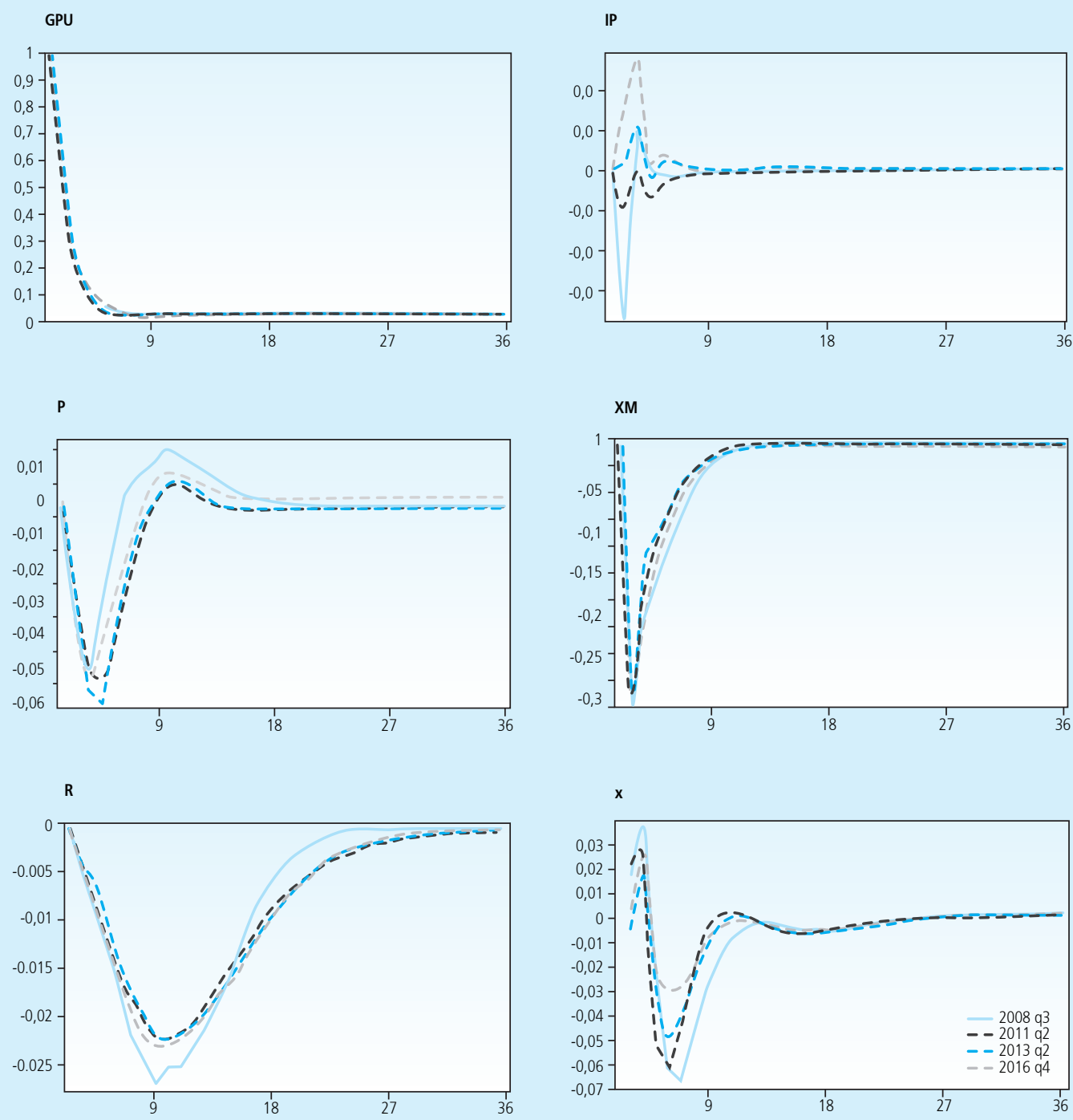

Source: Author's estimation.

Figure 4.

Dynamics following a global economic policy uncertainty shock: various global events.

Next, to examine the importance of GPU shocks, I show the forecast error variance of selected variables (i.e., output, prices, and trade balance) due to the policy uncertainty shock. Figure 5 shows that the contribution of GPU shocks to the forecast error variance of those three variables are consistently small. Nevertheless, the proportion of forecast error variance of trade balance is substantially larger than the other two variables. For all dates, GPU shocks explain around 3 to 4.5 percent of the variation in the trade balance whereas the shocks only explain 
around 0.04 percent of variability of inflation. Notice also that the forecast error variance of output decreases rapidly throughout the sample period. In early 2005, GPU shocks explain around 0.5 percent of the variability of output, but toward the end of sample period, the contribution of GPU shocks to the variablity of output falls to around 0.1 percent.
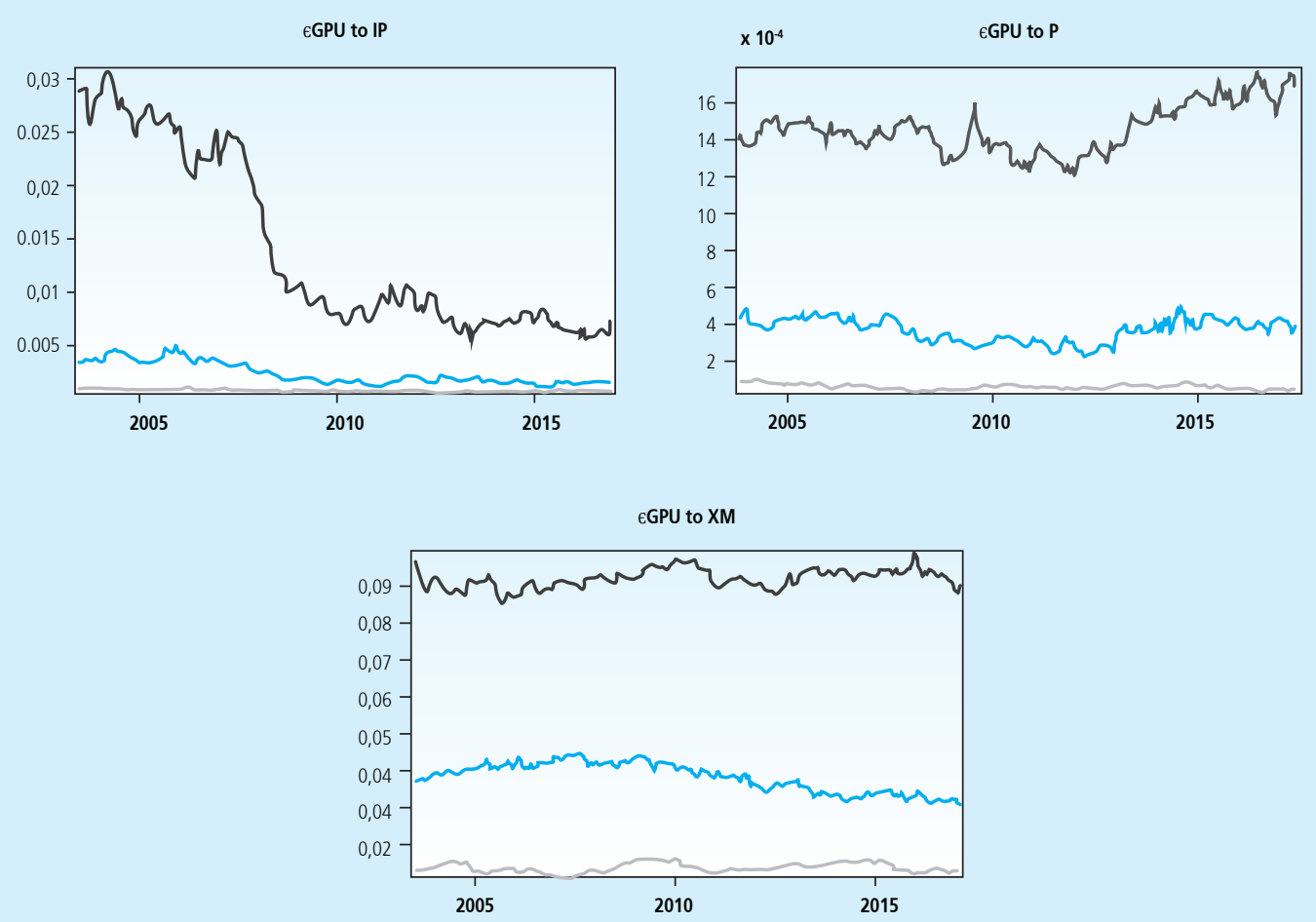

Source: Author's estimation.

Figure 5.

Forecast error variance due to GPU shocks: various dates.

\section{CONCLUSION}

I examine the macroeconomic impact of global economic policy uncertainty shocks to Indonesian economy using a time-varying Bayesian structural VAR (TVP-BVAR) with non-recursive identification method proposed by by Canova and Pérez Forero (2015). The empirical results show negative reactions of prices, interest rates, and trade balance following GPU shocks in all global events included in the study. Furthermore, the impact on output largely varies across events. Around the 2008 global financial crisis, a surprise increase in the GPU causes output to fall and despite the recent concern about US economic policy following the 2016 US presidential election, output increases on impact and rapidly moves back to its pre-shock level after 9 
months. However, the contribution of GPU shocks to the forecast error variance of output is very small and decreases rapidly over time-which indicates that GPU shocks have small real effects to Indonesian economy. Nonetheless, the proportion of the forecast error variance of trade balance due to the global economic policy uncertainty shocks is considerably higher than the forecast error variance of output and inflation due to the shock-which further suggests that, via international trade, a surprise movement of global economic policy uncertainty still could pose harm for Indonesia.

Caggiano et al. (2017) found the existence of a channel they called "economic policy uncertainty spillover". Via this channel, an increase in US economic policy uncertainty leads to a temporary contraction of Canada's economy because the uncertainty in the US fosters policy uncertainty in Canada which directly lead to a contraction on output. This finding, they added, is robust to an existence of a channel working through bilateral trade-although the trade channel only plays a minor role. If similar policy uncertainty spillover channel exists for the case of Indonesia, the decreasing contribution of GPU shocks to output indicates that, in Indonesia, this spillover channel is trivial and that trade channel plays a bigger role in the transmission mechanism of GPU shocks to the economy. Nevertheless, to validate this conjecture, I need to include an index measuring Indonesian economic policy uncertainty in the model. To my knowledge, no such index exists. Thus, I view this extension as an important avenue for future research. 


\section{REFERENCES}

Abrego, L. and O. Par. 2008. External Linkages and Economic Growth in Colombia: Insights from a Bayesian VAR Model. IMF Working Paper WP/08/46.

Andrle, M., R. Garcia-Saltos, and G. Ho. 2013. The Role of Domestic and External Shocks in Poland: Results from an Agnostic Estimation Procedure. IMF Working Paper WP/13/220.

Aswicahyono, H. and H. Hill. 2014. Survey of Recent Developments. Bulletin of Indonesian Economic Studies, 50(3): 319-346.

Baker, S., N. Bloom, and S.J. Davis. 2016. Measuring Economic Policy Uncertainty. Quarterly Journal of Economics, 131(4): 1539-1636.

Bernanke, B.S. 1986. Alternative Explanations of the Money-Income Correlation. CarnegieRochester Conference Series on Public Policy, 25: 49-99.

Blanchard, O.J., and M.W. Watson. 1986. Are Business Cycles All Alike? in: R.J. Gordon (ed.), The American Business Cycle, NBER and Chicago Press, 123-179.

Caggiano, G., E. Castelnuovo, J.M. Figueres. Economic Policy Uncertainty Spillovers in Booms and Busts. Melbourne Institute Working Paper No. 13/17. Online, https://ssrn.com/ abstract $=2972967$.

Canova, F. and F.J. Pérez Forero. 2015. Estimating Overidentified, Non-recursive, Time-Varying Coefficients Structural Vector Autoregressions. Quantitative Economics, 6(2): 359-384.

Colombo, V, 2013. Economic Policy Uncertainty in the US: Does it Matter for the Euro Area? Economics Letters, 121(1): 39-42.

Davis, S. J. 2016. An Index of Global Economic Policy Uncertainty. NBER Working Paper No. 22740.

Gauvin, L., C. McLoughlin, and D. Reinhardt. 2014. Policy Uncertainty Spillovers to Emerging Markets-Evidence from Capital Flows. Bank of England Working Paper No. 512.

Handley, K. 2014. Exporting under Trade Policy Uncertainty: Theory and Evidence. Journal of International Economics, 94(1): 50.66.

Handley, K., and N. Limão. 2014. Policy Uncertainty, Trade, and Welfare: Theory and Evidence for China and the U.S. NBER Working Paper No. 19376.

Kim, S. and N. Roubini. 2000. Exchange Rate Anomalies in the Industrial Countries: A Solution with a Structural VAR Approach. Journal of Monetary Economics, 45: 561-586. 
Klößner, S. and R. Sekkel. 2014. International Spillovers of Policy Uncertainty. Economic Letters, 124(3): 508-512.

Österholm, P. and J. Zettelmeyer. 2007. The Effect of External Conditions on Growth in Latin America. IMF Working Paper WP/07/176.

Primiceri, G. 2005. Time-varying Structural Vector Autoregressions and Monetary Policy. Review of Economic Studies, 72: 821-852.

Sims, C.A. 1986. Are Forecasting Models Usable for Policy Analysis? Minneapolis Federal Reserve Bank Quarterly Review, 10: 2-16.

Solmaz, S. and M.T. Sanjani. 2015. How External Factors Affect Domestic Economy: Nowcasting an Emerging Market. IMF Working Paper WP/15/269.

Voss, G.M. and L.B. Willard. 2009. Monetary Policy and the Exchange Rate: Evidence from a Two-country Model. Journal of Macroeconomics, 31: 708-720. 
148 Buletin Ekonomi Moneter dan Perbankan, Volume 20, Nomor 2, Oktober 2017

Halaman ini sengaja dikosongkan 